\title{
In reply to: Helmich and Bloem (2020) "The Impact of the COVID-19 Pandemic on Parkinson's Disease: Hidden Sorrows and Emerging Opportunities"
}

\author{
Emma Edwards ${ }^{\mathrm{a}, *}$ and Camille Carroll ${ }^{\mathrm{b}}$ \\ ${ }^{a}$ Livewell Southwest CIC, Plymouth, Devon, UK \\ ${ }^{\mathrm{b}}$ University of Plymouth, Faculty of Health, Plymouth, Devon, UK
}

\section{Dear Sirs,}

We read with interest the paper by Helmich and Bloem outlining the Hidden Sorrows and Emerging Opportunities that the COVID-19 pandemic may bring to the Parkinson's population [1]. As we are navigating our way through the complexity of providing support to people with Parkinson's who are self-isolating, we find that our experience resonates with what the authors describe. However, an additional Hidden Sorrow is the impact on caregivers, and the relationship between them and those they care for. We present 3 vignettes (from just one day of community Parkinson's nurse home visits) that illustrate this important, and yet easy to overlook, issue:

Case 1: Mr. N, 77 years old, has had Parkinson's disease dementia for a few years. He is cared for by his wife at home, and has been having regular respite breaks in a local nursing home. The care home is not accepting respite admissions currently due to managing their risk of COVID-19. His wife has friends that would normally sit with her husband whilst she goes to the shops or hairdressers; they are

\footnotetext{
*Correspondence to: Emma Edwards, Livewell Southwest CIC, Plymouth, Devon, UK. E-mail: emma.edwards17@nhs.net.
}

no longer allowed to visit. The Parkinson's groups they both attend in the city have shut for the time being, although one is offering a monthly video meeting. Mrs. $\mathrm{N}$ did 'attend' a meeting, but her husband nearly fell over during the meeting and so she is not sure if she will attend the next. Mrs. $\mathrm{N}$ tells me that she is struggling with her patience and feels guilty that she is resentful that she can't leave the house. She tells me that being with her husband 24 hours a day has brought it home to her that she won't be able to cope once the illness progresses. Mrs. $\mathrm{N}$ is a talkative lady and $\mathrm{Mr}$. $\mathrm{N}$ rarely initiates conversation these days due to word finding difficulties. The silence in the house upsets her. She is considering whether, once the care homes open again to admissions, her husband would be better off living there on a permanent basis. These thoughts, once again, compound her guilt. We agree together that an immediate referral to Adult Social Care would be appropriate so that more practical support can be offered to them both.

Case 2: My next visit is to Mr. P, 69 years old, who is entering a more complex phase of his condition and is having significant motor fluctuations. He experiences anxiety most days and this has increased recently due 
to his worries about contracting COVID-19. Due to his asthma and Parkinson's, he is self-isolating with his wife at home. His wife is upstairs when I arrive but later joins us. She sits at the table behind her husband's chair. Mrs. P looks irritated and exhausted, and shakes her head when her husband speaks. I ask her if she is okay. She tells she is frustrated that she has to self-isolate due to her husband having Parkinson's whilst she is perfectly healthy. Mrs. P tells me she feels guilty for thinking like this and is aware that feelings of resentment are rising. She says she is becoming more stressed due to their increasing arguments and her husband's inflexible thinking. She always knew he was anxious, but hadn't appreciated the extent of it, as pre-lockdown she was out of the house for many hours in the day. She tells me that she can't wait to get out of the house when the restrictions are eased so that she can have time by herself. Mr. P thinks it will be years before he has the confidence to leave the house again, and that she will be going out alone. A referral to psychological services is offered to Mr. P to address his anxiety; he declines at this time. However, his wife agrees that she will contact the local care advisor from Parkinson's UK for some advice for herself. A small adjustment is a made to Mr. P's medication regime to improve wearing off.

Case 3: My last visit of the day is to a 65-year-old man with Parkinson's whose wife recently died. He wasn't able to be with his wife when she died due to COVID-19 restrictions, or attend her funeral. He now has visual hallucinations of his wife in his house. His daughter now lives at the house and reassures him often, but is coping herself with feelings of bereavement. She says that repeatedly telling her father that her mother has died and that the hallucinations are not real is becoming difficult for them both. His daughter would like to have some help in the day from a care agency but they are currently not taking on new clients due to worries over COVID-19. We agree that talking to a local bereavement service may be helpful for the family, so I leave them with that number. I also prescribe a medication that will hopefully help the hallucinations. As I am leaving, and away from her father, she confides in me that she would like to move out again, but will stay for as long as she can.

The role of caregivers in contributing to patient wellbeing is well established, as are the importance and challenges of recognising, evaluating and supporting carer strain [2]. With most clinic assessments currently being conducted remotely, opportunity for caregiver input, or checking in with the caregiver separate from the patient are limited. Carers are no longer able to access their existing support systems. As care providers, we need to develop processes for evaluating carer strain within our new framework of working, understanding that we may not have usual resources at our disposal to mitigate and support. As illustrated by these vignettes, community Parkinson's nurses can play a critical role in identifying the issue, evaluating its severity and likely consequences, and implementing solutions. Parkinson's nurses are a vital spoke in the integrated model of care we deliver to our community of people with Parkinson's and their loved ones, not only for their specialist Parkinson's knowledge, but also for their links within the interdisciplinary team and broader community.

\section{CONFLICT OF INTEREST}

The authors have no conflict of interest to report.

\section{REFERENCES}

[1] Helmich RC, Bloem BR (2020) The impact of the COVID19 pandemic on Parkinson's disease: Hidden sorrows and emerging opportunities. J Parkinsons Dis 10, 351-354.

[2] Mosley PE, Moodie R, Dissanayaka N (2017) Caregiver burden in Parkinson disease: A critical review of recent literature. J Geriatr Psychiatry Neurol 30, 235-252. 